expanding her role. As usual, there is a tendency to evaluate these services in terms of how well they are received by the professionals rather than whether the patients get any better!

Some members of the RCGP have recently started interesting pioneering work on patient participation groups in relation to practices. The April issue of their College's Journal contains an account of a meeting at the beginning of this year showing that on the whole these groups are of great value, though there have obviously been problems on how to recruit the right sort of person into them. If medicine is seen as a service to the community, those who would be interested in how good it is need not necessarily be patients, or even relatives of patients. As a sort of general practice equivalent to the Community Health Council, they may well have more value than the hospital-based groups which, as is well known, have had a very mixed reception.

I, personally, have been very stimulated by contact with these new advances in community health care, and for once have not been sorry to find myself on yet another committee. I wrote this just before leaving for a trip around various countries in the Far East, from which I will have returned by the time this is in print. I expect my trip may give a different slant to my thoughts on medicine in the community.

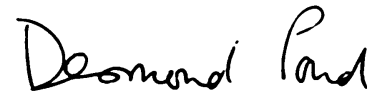

\title{
A Case for Clinical Research
}

\author{
By Ming T. Tsuang
}

My psychiatric orientation is deeply rooted in my student days at 'The Maudsley', and my study at the then MRC Psychiatric Genetics Unit under Eliot Slater moulded my 'British approach' to psychiatry. My understanding, (with which the reader may not agree) of this approach is that it is clinical, empirical and practical. After I left Britain in 1965, I participated in the International Pilot Study of Schizophrenia (IPSS) as an investigator from Taiwan, and I firmly believe that the study could not have been done without the British group's contribution, for the success of IPSS was due to the application of these same clinical, empirical and practical approaches.

In 1971, I moved to the United States, but 'British orientation' has continued to dominate my psychiatric work ever since. I have found that the day-to-day practice of treating patients is the best source of new ideas for clinical research. In my own experience of running an in-patient service of the University of Iowa Psychiatric Hospital, I have learned much from my patients, medical students and colleagues. Medical students sometimes ask questions which seem naive or simple, and which we often answer without serious consideration; in fact we may mislead them with answers based not on facts but on our own 'experience'. Often we search the literature only to conclude that we cannot answer their questions without conducting some pilot research of our own, and it is when a pilot study is initiated out of such clinical necessity that residents feel it to be useful and not merely of academic interest. There is a misconception among some clinicians that research has to be perfect and highly sophisticated and that detailed knowledge of methodology and statistical analysis is always essential, and many are consequently scared away. We are not all born to be mathematically minded. Many interesting and important clinical observations based on small numbers of cases have been made without the need for statistics. Obvious results do not need any statistical test to show a 'P level of significance'. In fact a significance level may give results a misleading air of authority, by which clinicians may be blinded and fail to pay attention to sample size, or to the characteristics of the population from which the sample was drawn.

Another misconception is that to carry out good research one has to have an adequate grant for a full-time job. That is not true: many good pilot studies have been conducted by busy clinicians who did not seek additional funds. Of course, to confirm or refute the results of clinical pilot studies, to test some hypothesis, or to look at aetiological problems on a large scale, time, money and sophisticated research methodology are certainly needed.

But every clinician can be a researcher too, depending on whether he is interested in solving his own clinical problems or satisfying his own curiosity. If research is combined with clinical activities, much time and energy can be saved. It should become a habitual pattern of his daily clinical practice to ask and try to answer questions, even if he is working with a small sample.

Practical and clinical considerations apart, I feel that clinicians who are involved with patients have a responsibility to identify problems and carry out pilot studies for non-clinicians who conduct basic scientific research, because we cannot afford to let our non-clinical colleagues take over completely research dealing with clinical problems. We cannot criticize them for doing studies with no clinical relevance, if we do not tell them about our own clinical problems and provide them with new ideas for research. We should continue to collect clinical, empirical and practical data, even 
though they are not 'clean'.

In lowa, we encourage all residents to take the opportunity to do clinical research. Once a resident has left clinical activities for research, he tends to feel that he has all the time in the world, being free from day-to-day clinical activities, which always demand immediate attention. So he tends to design an ambitious project, dreaming that his first and final piece of research may win him the Nobel Prize. He forgets that his time is limited, and may not realize that it may not be feasible to solve the research problems which he would like to tackle. Residents also attempt to do research on too many areas at once; they try to convince one that they can accomplish all they propose to do, and if one doesn't insist on their tackling only one research problem they will use up all their time but accomplish nothing. They then feel guilty and decide that research is difficult, complicated and uninteresting. So from the beginning $I$ insist on the basic principle of tackling one clinical problem only.

The supervisor should evaluate, together with his residents the feasibility of conducting the research work involved within a limited period of time. Literature reviews should follow, and availability of material should be examined. I always ask those residents who want to publish their research work to summarize their literature review in writing and to use this as a basis for the introduction and discussion parts of their final paper. Even for those who are not interested in publishing a paper (which is very rare in lowa!), it sharpens the focus of their study if they systematically write down what they would like to do. It is also advisable for them to discuss the research proposal informally with colleagues or to present the proposal to a research seminar, so as to collect comments and criticisms from other workers, particularly with respect to feasibility. When the research is under way, it is still advisable to continue some informal discussion with interested colleagues. When work is accomplished, it should be presented again before final writing and submission for publication.

Residents should not be misled into thinking that once the work is completed it is an easy task to write and publish it. My experience is that residents tend to put far too much into the first draft. The draft becomes diffuse and lacks focus. Here again the principle of reporting on only one main finding should be emphasized, and the writing should focus on that point alone. Other points can be discussed subsequently, but not in the first draft, nor muddled up with the main results. The shorter the paper the better the chance of it being accepted.

It is important to ask residents to write up their research results within the time allotted for research. Once they return to clinical duties they tend to be too busy to meet the deadline which they have set themselves. They then feel guilty and have to think up excuses.

If the resident has not had previous experience of writing a paper, it is the responsibility of the supervisor to make that first draft into a publishable piece. The work involved in preparing the draft depends on how keen the resident is to learn the skills of writing for publication. Some like to learn step by step, and the supervisor has to discuss every detail, and help to produce a second, third or perhaps even tenth draft. However, if the resident is not interested in learning how to write a concise paper, the supervisor should do most of the work himself, in collaboration with the resident, and complete the task as soon as possible. I always promise that if the first draft can be produced within a year or so after the completion of the work, the resident will be entitled to claim the first authorship or sole authorship. Some residents tend to procrastinate and end up producing nothing on paper; or after one year the resident may live elsewhere and letters asking for the first draft receive no reply. In this situation, I usually write the first draft and publish the final paper with the resident as the second author.

It may sound as if having a block of research time is an ideal arrangement, but in practice this may not be the case. If residents are forced to do research in a particular period of time, they may lose enthusiasm and interest. It may be more fruitful if they decide to solve clinical problems that arise during their clinical work by carrying out research simultaneously. Such well-motivated residents often carry out the research with initiative and complete the task, even down to the nitty-gritty of publication, and they should be encouraged by letting their research be published as a singleauthor paper.

I recall my experience at the Genetics Unit. In addition to finishing writing my thesis, I also completed a piece of work which Dr. Slater had assigned to me. Before I left the Unit, I gave him the results and told him to do whatever he liked with my report; as far as I was concerned I had merely fulfilled my responsibility as a student and he could publish the material without my name, since I did not have time to write it up formally before my departure. I have never forgotten the word 'preposterous', which he used to express his disapproval. He asked me to write the first draft when I got back to Taiwan and then to send it to him. He said I should be the sole author even though he had assigned me to do the work and would spend time revising it. It was his responsibility as a teacher to do it for his student: 'My teacher did the same for me-do the same for your students'.

In the preface to his book, Schizophrenia: Towards a New Synthesis, John Wing describes three characteristics of the late James Shields' work: eager curiosity, high scholarship and balanced judgement. Clinical research should originate from eager curiosity through day-to-day practice; without such curiosity clinical research can never be initiated. All clinical research has originated through curiosity and the desire to solve clinical problems. The empirical approach will encourage a high level of scholarship. Finally, balanced judgement is vital in order to apply practically the research findings.

Ming T. Tsuang, Visiting Professor of Psychiatry, University of Oxford 